See discussions, stats, and author profiles for this publication at: https://www.researchgate.net/publication/325771921

\title{
Critical Discourse Analysis and the challenges and opportunities of social media
}

Article in Review of Communication · July 2018

DOI: 10.1080/15358593.2018.1479881

CITATION

READS

734

2 authors, including:

Gwen Bouvier

National University of Ireland, Maynooth

15 PUBLICATIONS 65 CITATIONS

SEE PROFILE 


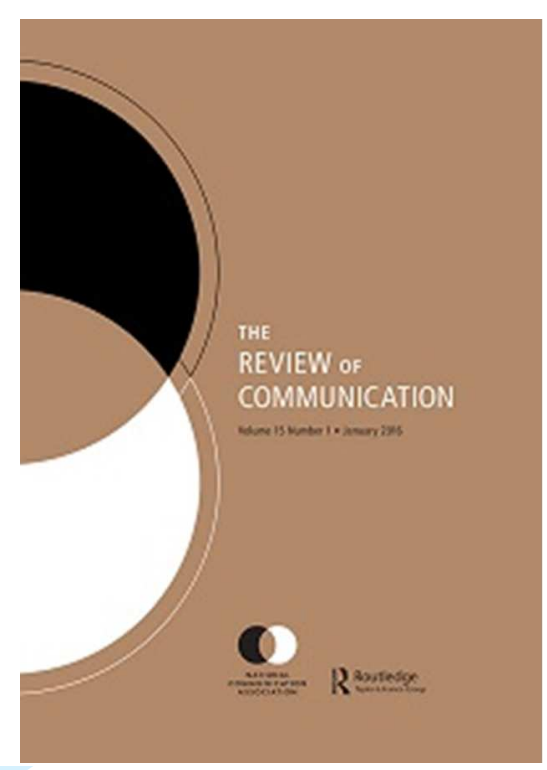

\section{Critical discourse analysis and the challenge of social media: the case of news texts}

\begin{tabular}{|r|l|}
\hline Journal: & The Review of Communication \\
\hline Manuscript ID & Draft \\
\hline Manuscript Categories: & Original Articles \\
\hline Keywords: & Critical Discourse Analysis, social media, news, ideology, sourcing \\
\hline \multicolumn{2}{|}{} \\
\hline
\end{tabular}

\section{SCHOLARONE \\ Manuscripts}


Critical discourse analysis and the challenge of social media: the case of news texts Gwen Bouvier and David Machin

\title{
Gwen Bouvier
}

Gwen Bouvier is Senior Lecturer at Orebro University, Sweden. Her main areas of research interest are social media, discourse, and news and her publications have drawn on multimodal and discourse analysis. Her latest publications include Bouvier, G. (ed) (2016) Discourse and Social Media, London: Routledge; Bouvier, G. (2015) 'What is a Discourse Approach to Twitter, Facebook YouTube and other Social Media: connecting with other academic fields', Journal of Multicultural Discourses, 10(2): 149162.

\section{David Machin}

David Machin is Professor of Media and Communication at Orebro University Sweden. He has published widely in the areas of Critical Discourse Analysis and Visual Communication. His publications include How to Do Critical Discourse Analysis: A Multimodal Introduction (2012), The Language of Crime and Deviance (2012) and Visual Journalism (2015). He is co-editor of the international peer reviewed journals Journal of Language and Politics and Social Semiotics.

Wordcount 7827

\begin{abstract}
CDA is a particular strand of discourse analysis which has been interested in the role of language in the functioning of society and political processes. It has tended to target texts produced by elites and powerful institutions, such as news and political speeches, with a view to revealing the kinds of discourses used to maintain power and sustain existing social relations. However, since the internet and social media have come to define much of the way that we communicate and run our lives it has become clear that CDA should engage more with language and discourse in this context. Looking at how CDA approaches news texts, we show that social media bring a number of challenges as regards how we formulate the relationship between texts and ideology, and how we view the relationship between the author and reader. This creates a challenge for how we collect data and the very methods we need to carry out analysis.
\end{abstract}


Key words: Critical Discourse Analysis, social media, news, ideology, sourcing

\section{Introduction}

CDA is a particular strand of discourse analysis which has been interested in the role of language in the functioning of society and political processes. Emerging out of Critical Linguistics in the late 1970s, CDA saw "language as a form of social practice" (Fairclough, 1989: 20), which is used to legitimize, maintain and naturalize forms of social power and inequality. Here power means the ability not only to coerce through things like the military, legal or penal system, but where there is control over the kinds of ideas and values used to create our societies. These will be found throughout institutions and organizations such as schools, businesses and media (Simpson \& Mayr, 2010: 2). The language and communication found in, and produced by, these institutions and organizations will reflect the interests of those in power and in a sense will create a kind of 'consent' that they are common sense and best for all interests. CDA is therefore interested in close analysis of how language plays a role in creating and sustaining these dominant interests, for example, as regards class relations, racism and sexism, with the ultimate aim of resisting social inequality (Van Dijk, 1998: 1).

In $C D A$, analysis has tended to target texts produced by elites and powerful institutions, such as news and political speeches, with a view to revealing the kinds of discourses used to maintain power and sustain existing social relations. However, since the internet and social media have come to define much of the way that we communicate and run our lives (Thurlow, 2011), there have been obvious calls that CDA engage more with language and discourse in this context (Bouvier, 2015). Social media have also become integrated with the way that official institutions and organizations now operate, since it is also here that social and political issues are represented and debated (Mautner, 2005). But whereas former 'elite' texts appeared to provide clearer routes to tracing dominant ideologies, social media mix voices and genres of communication, and these are shifting combinations of interactions within and across platforms, often which feed into more traditional media forms (KhosraviNik \& 
Unger, 2015). This creates new theoretical and methodological challenges for CDA. News itself has become highly integrated into social media, both as a way of sourcing and delivering content. The route to identifying and understanding elite ideologies has changed. This has resulted in texts that are certainly less static, which look very different, and which are generated and received in very different ways. And, we show, news sits in a broader media landscape where flows of knowledge must be characterized in very different ways, where authorship and authority in texts needs to be rethought. In this paper, we identify the nature of these challenges as regards the way that CDA approaches news texts, both as regards how we can characterize them as vehicles of ideology and in terms of how they should be approached as data.

\section{Doing Critical Discourse Analysis}

There are different ways of doing CDA and these involve a range of different and overlapping concepts (Wodak \& Meyer, 2001). But put in simple terms, CDA is problem, not theory driven, where the aim is to analyze language use to show "strategies of manipulation, legitimation, the manufacture of consent, and other discursive ways to influence the minds (and indirectly the actions) of people in the interests of the powerful” (Van Dijk, 1995: 18).

In CDA it is assumed that those in positions of power will attempt to disseminate discourses (Foucault, 1972) throughout society that serve their own interests. Discourses are like models of the world that explain why we do things, how we understand events and processes, what kind of people exist in the world (Fairclough, 1992). Such discourses can be found by looking at more subtle uses in language. For example, it has been shown that in news reports reported speech can carry nonexplicit meaning (Caldas-Coulthard, 1994). For example:

The management stated that working conditions were of the highest standard

The workers claimed there were problems with working conditions 
The difference between 'stated' and 'claimed' here implicitly affirms the stance of the management as more credible than the workers, who make mere claims. Such smaller uses of language can build up in a text, for example, to reinforce a well-trodden discourse that trade unions are self-motivated, against the wider interests of society.

For CDA, therefore, the aim is to critically study the language found in texts to reveal the kinds of discourses being disseminated. At a surface level, Fairclough (2001: 27) points out, these may appear as "universal and commonsensical [yet] can often be shown to originate in the dominant class". While CDA tends to argue that society is complex and has many different kinds of power relations between groups, for example men and women and between ethnic groups (Fairclough, 2001), as van Dijk (1995: 250) points out the focus has been on "elites and their discursive strategies for the maintenance of inequality". And importantly, one massive resource for the maintenance of power is having "privileged access to discourse and communication" (Van Dijk, 1993: 255).

Importantly for CDA, discourses are interconnected with social practices. Social practices are the doings of discourse (Fairclough, 2000). Discourses provide the 'scripts' for acting in society, and in turn social practices embody discourse in the material world that we meet.

While people may encounter dominant discourse through mundane everyday situations such as through chatting over coffee, the focus of CDA has been the major institutions such as the news media which are the major channels for such views, where elites transfer their discourse to lower classes (Van Dijk, 2008). While such major news institutions still have importance, social media have changed the way that information and knowledge are exchanged in society. They have changed the routes and patterns by which this is done, created shifts in the genres and discourses through which this takes place, and importantly have changed the nature of authorship itself. All of these require that CDA reconsiders how elites can directly control discourse and if this now becomes of a different order, requiring new models and new tools for analysis.

\section{Text analysis in the context of production and reception}


CDA is clearly based on a number of assumptions about the nature of ideology found in texts and the value of studying the discourses disseminated by elites of powerful groups by major institutions. News organizations in this sense have logically been key sites for the study of language and communication. However, since the mid-2000s in particular, the media landscape has transformed. While we still find many of the former top-down monolithic media intact, these sit alongside and are integrated with newer forms of media that involve different kinds of channels of content flow and different kinds of 'producer-receiver' interactions (KhosraviNik \& Unger, 2015). The challenge for CDA is to grasp what this means as regards carrying out critical language analysis, to reveal how dominant ideologies are disseminated in a society.

In fact, over many years CDA has been criticised for being overtly text focussed, and for failing to account for processes of production and reception (Philo, 2007). In practice this has meant that the nature of discourses found in texts through linguistic analysis are rather simplistically understood. While a number of key authors in CDA have called for the inclusion of these as part of the process of analysis (Fairclough, 2000) this has never really materialised. As a first step to looking at the challenges for CDA as regards social media, we begin by asking what former challenges have not so well been taken up. While social media bring new challenges, they follow some of these earlier patterns.

A CDA approach to a news text that represented an industrial dispute may be able to show that reports always subtly favour management against workers. However, the ideology found in such texts may not be so much the 'bias' or ideology of an individual journalist or news outlet per se. Much news content comes from four major global news agencies that are linked into financial markets and corporate networks (McChesney, 2004). These agencies produce stories aimed at and packaged for their major customers; for the most part media corporations in wealthier Western societies. The bulk of the income of these agencies comes from delivery of data for financial markets (Loomis, 2007). Studies of the output of these news agencies show that they tend to select and 
produce stories based around a limited set of values targeted at their main western markets (Harcup \& O' Neill, 2010). In other words, what events are easily meaningful and unambiguous for those news audiences? As we will show shortly, such 'news values' later become integrated into the way social media identify things like 'trending topics'.

It has also been shown that up to $70 \%$ of what appears as news is produced by PR companies, who supply ready to use stories and scripts for broadcasters (Lewis et al, 2008). Further, much news is sourced from official institutions, such as the police, courts and local-authorities (Fishman, 1980). This has the advantage for news outlets that they provide regular and predicable sources of events that can be presented as newsworthy. But it means that the news is basically an official view of the world. For example, crime is seen from the point of view of law enforcement rather than those who inhabit the socially deprived areas where it tends to take place (Mayr \& Machin, 2012). As we look to how social media provides sourcing for news, we also have to ask what kinds of organisations will tend to be supplying content.

Critics of CDA have argued that challenging power relations through drawing out ideologies in news texts can be rather simplistic without understanding how what we find in those texts is a result of these kinds of processes. An analysis carried out in CDA that looks at language alone is unlikely to throw any deeper insights into how ideology is disseminated (Philo, 2007). In fact, as Philo argues, such a text analysis should be done as part of a production study, showing how journalists write, how they compose for different markets, for multiple readerships, using particular sources for practical and economic reasons (2007: 192). In one sense here, ideology is built into the nature of news per se and the processes that lie behind the text itself.

Put another way, the critical study of language may involve documenting the use of language. But it also means studying how it is used in specific contexts, with a view to revealing who has control over it and how this control is exercised. Since the rise of social media, however, while these production 
factors still apply, there are some additional challenges to take account of. To some extent these transform production, reception and the genres of communication that are involved.

\section{How social media has changed news}

Over the past decade we have seen the huge changes in the media landscape where social media and the internet allow citizens, civic society, politicians and business elites to bypass traditional mass media and directly communicate with each other (Paulussen \& Harder, 2014: 543). The demand of the internet-based media environment, with the need for constant updates and massive competition for clicks, has also created a further challenge for many long-established traditions in journalism and news production, leading also to the need for radically different business models (Picard, 2014: 273). Journalists now work in an environment where there are blurring boundaries between citizen journalists, bloggers, and other communication roles (Carlson \& Lewis, 2015). All these factors suggest new relationships between producers and readers. They also mean new production processes to grasp in order to understand the social goings on behind news texts. In both cases, there are implications for how we attribute discourses and ideology in texts.

\section{Social media and the sourcing of news}

Social media itself has become a core part of sourcing news content (Hermida, 2012). This can mean breaking stories by using citizen journalist reports on Twitter, or having journalists scouring local community networks on social media for locally trending story ideas. This has been one way to engage audiences in an environment where there has been a massive decline in interests in mainstream news (Picard, 2014). Job vacancies at local news outlets often include things like 'social media journalist' or 'engagement journalist'. At the time of writing, Twitter itself had become what some observers called a part of news production's "technological infrastructure", where news outlets find stories but also where they monitor and copy each other (Paulussen \& Harder, 2014: 543). Here we may find the views of the elite sourced particularly from Twitter. But we may also find local and non-elite material. 
There were celebratory accounts of the use of Twitter to break and source stories, for example in the coverage of earthquakes and uprisings (see Bruno, 2011; Newman, 2009), arguing that Twitter users function as a kind of early warning system that can then be followed up by professional journalists (Bruno, 2014), what Allan (2013) calls 'citizen witnessing'. Citizen generated content can be used, it has been argued, as a form of "liberation technology" (Diamond, 2010: 70), where governments, election processes, police actions and so on can be monitored. Such observations, from the point of view of CDA, suggests a shift away from the manner in which elites may be able to more directly control discourse. For example, where crime can become less defined by law enforcement organizations, and where social media carries footage and viewpoints from those experiencing events, as we have seen with events of police violence against black citizens in the US. Indeed, if the news media engage more with the stories and events running across social media, does this mean that this sense of top-down ideology becomes less of a straightforward idea? At least the task may be more to look at how 'citizen' viewpoints become re-contextualized as they become news.

Others journalism scholars pointed out that most citizen generated content was simply absorbed into the typical kinds of news values and frames used by mainstream outlets (Allen, 2006). So a citizen generated photograph from a war zone is used by a news website not in a way that helps to provide context specific information to that situation, but simply as part of the usual news frames employed for such conflicts in remote places. For example, it has been observed that conflict images often depict children as part of signifying societal breakdown and to chime with western readers (Parry, 2012).

In such cases, social media viewpoints become simply shaped to fit the traditional forms of stories supplied by the news agencies. Keller (2011) points to how such citizen reporting can simply have a legitimizing effect on mainstream news presentations. Social media-generated news out of a conflict area signifies on-the-spot immediacy, even if no attempt is made to provide any further context. And it allows the news to give a sense of presenting the voice of the ordinary person, bringing a freshness 
to stale formats (Anden-Papadopoulos \& Pantti, 2011), or to show that it has become, like the rest of the media landscape, more democratised. Here the citizen voice does not challenge the top-down elite discourses, but is used a resource to further legitimize them.

For a researcher seeking to carry out CDA, a single news text about a conflict in remote place may contain elements of citizen journalism, some eyewitness comments about the brutality of the regime's police, an image of a marketplace after an explosion taken by a mobile phone. In the case of such a text, what is it about production that we need to know in order to avoid the kind of simplistic analysis that lead to the likes of Fairclough (1995) urging that CDA must grasp something of the social goings on behind texts? In this case, we may have some of the former top-down processes, as found in the earlier media landscape. So the texts are result of the work of news agencies, are advertising driven, and we find a dominance of elite sources. Ideology here therefore is built into news at a systemic level. But here social media introduces other elements that themselves remain to be assessed and understood. Clearly for CDA, in this environment of increased diversity of sources one aim would be to identify where and if there is space for competing discourses and what these are. If we find a massive increase in citizen reports, sourced from social media, to what kinds of social practices are these related? Are there spaces here where grassroots views are permitted, for example in crime and policing, where police brutality against black citizens in the US has be highlighted through social media, but other areas where it is excluded?

\section{Social media and how we access news}

Social media have transformed the delivery of news, becoming one of the main sites where readers access news and where outlets can deliver tailored content to personal needs (Mortimer, 2014). Since the 1990s it was observed that news delivery became much more focussed on niche market groups, which were of high value to advertisers (Harcup, 2015). Individual journalists began to be trained in how to write in ways that addressed such niche markets, marking a shift away from audiences being addressed as citizens to them being addressed in the first place as consumers 
(Machin \& Niblock, 2006). But in the social media environment this targeting of news content to consumer preferences shifts to a new level as stories are delivered to customers driven by data analytics. Now news organisations constantly monitor traffic via web analytics. Patterns of reading are traced and modelled and resources then shifted to productive areas (Linford, 2015). Such patterns are then used to process complex data to profile news consumption with consumer behaviour.

The links between social media platforms and other kinds of sites in this situation, it has been argued, becomes a matter of corporations looking to lock users into their own chain of platforms in order ultimately to deliver to advertisers (Van Dijck, 2013). This may include email, newsagglomeration-sites, tablet-interfaces, platforms for television and movie delivery, and other social media. Here news organisations will need to ensure that they are favoured by the kinds of algorithms used at any time by dominant social media platforms, such as Facebook. Even here it has been argued that algorithms themselves become the shapers of discourse, or social relations (Bouvier, 2015). In other words, the discourses presented to any individual through news, entertainment, and other things 'you may also like', are patterned in ways aligned to your previous online activities, which include consumer behaviour (Doctor, 2010).

But what does this mean as regards power over discourses? In this sense the news reader, clicking on an item signalled as 'you might also like', may have more choice. They may have escaped the top down, distant, elite voice of the news reader delivering a bulletin to a whole country at a set time. But according to the likes of Dean (2010) these social media platforms and networks of communication are about capturing us into patterns of consumption. Social media in this sense, we might argue, offers "a confined and controlled space for semi-public interactions, under the conditions of a commercial logic" (Hintz, 2016: 327). Media and Communications scholars have long documented and expressed concern over the influence of advertising over news content (Curran \& Seaton, 2010), but this is different. It has been argued in CDA that processes of marketization, 
especially since the 1990s, have been penetrating deeper into all parts of society, even those parts normally operated along completely different principles such as our major public institutions (Fairclough, 1992). News, in the social media environment, must also be thought about not in terms of a site for civic public debate dominated by elites, but as something fundamentally organized and created based on marketization and commodification.

\section{Social media and the decline of the authority of the text}

With the rise of social media, it has been argued that the relationship between the public and media has changed (Murthy, 2010). In the pre-social media era highly centralized and monolithic media such as national newspapers were consumed in a top-down fashion by the public (Gilmor, 2006). Such media provided highly influential focal points for civic debate within any society, and news wielded much power over discourse. This, along with other powerful state institutions such as schools and politics, provided, or exerted, a powerful sense of collective culture and of what was shared knowledge about the world (Beck 1996). Here, for CDA, the analysis of texts can be one way to access how such collective culture is defined in this top-down fashion.

But scholars point to major shifts away from centralised state power with a decline in the influence of the older institutions to govern and regulate society (Beck, 1996). There has been a process of devolving those roles taken by former state institutions to private and semi-private organisations (Jessop, 2007). The major state institutions that wielded the power of the old centralized state, including political institutions and the news media, fall into decline and lose their former powers (Beck, 1996). Here too, we find a decline in the power of the elites and professions who controlled those institutions (Freidson, 2001).

Such societal shifts have led to what Zizek (1997) called a collapse of the 'big other'. By this he meant the loss of any centralized, dominant form of institutionalised knowledge, which provided a sense of consensus about ideas and identities. Dean (2010:5) argues that this decline of a central 'symbolic' has been replaced by the niched yet fragmented and overlapping patterns of connectivity 
created by social media, comprised of bundles of entertainments, consumerism and more localised interests. The former top-down sense of collective culture providing authoritative and consensual knowledge thus has become replaced by diverse and fragmented user opinions on social media platforms like Twitter, Facebook, etc. News ceases to provide the central symbolic but now looks to engage interest of individual users who operate within communities of connectivity. As previously mentioned, recruitment listings in the news industry began to call not for 'reporters' but for 'engagement journalists'.

In this new context, news simply cannot offer itself to readers through the same kind of voice of authority as in a former era, something acknowledged by news editors (Machin \& Polzer, 2015). Readers expect to be engaged in a level way, already as knowers and as having specific interests and ways of viewing the world. This is simply how news readers in the social media environment expect to be engaged. Here in fact, the very ideas of 'readership' and 'authorship' themselves become unstable. As Kress (2005: 19) points out "When everyone can be an author, authority is severely challenged". The very nature of communication which gave the author power, established over several centuries, has simply changed as has the authority vested in the author. For Kress, in particular this demise in the power of the author means that what is produced in texts is no longer seen as 'knowledge' in a former sense but rather as information and, as Dean (2010) argues, is mostly treated as opinion rather than fact. This has implications for how 'news' can be presented to a reader. A click-bait headline appearing in the new column of your social media page does not claim the weight of formal authority, but as 'something else you might like'. And in terms of authorship, the news item is no longer read as part of a former media genre, the newspaper, where authorship is provided by the name 'The New York Times', which occupies a huge city center building. The user will have less interest in the 'authorship' as in whether indeed it fits with their realm of information needs. 
Kress (2005: 10) argues that now readers fashion knowledge themselves, using information supplied in texts where there is a culture of using such information in relation to solving immediate problems, fulfilling needs, or requirements. News formerly carried authority, providing a top-down sense of shared knowledge and culture. It was the voice of the Zizek's 'big other'. But this would no longer be acceptable to readers who need to be addressed as equal authors, as holders of opinions.

This decline of the 'big other', of the monolithic media, and a sense of monolithic audiences, presents new challenges to CDA as regards how the dissemination of ideology can be accounted for. But so too does it ask for new ways of thinking about readership. Readers gain power in a sense as they are addressed as individual users with information needs. And as authorship ceases to hold power 'big knowledge' itself declines. For CDA, here the challenge comes to look at the kinds of discourses and ideologies that are carried across these communities of opinion, and to understand more about what this means as regards how dominant discourses become disseminated and shaped within these. This brings us onto our next section.

\section{Reading ideology in texts}

One other major criticism of the way that CDA deals with news texts and ideology that we have not yet addressed, is that it has paid little attention to how news audiences deal with news discourses (Philo, 2007). As such, it could be argued that what CDA produces is little more than a scholarly reading of a news text (Widdowson, 1995). Here, social media offer a range of possibilities, yet again the challenge is how we approach these.

Communications scholars have argued that one central question to answer as regards news is how audiences relate to the discourses produced by journalists (Hall, 1986). If we want to understand and challenge dominant ideologies and the social relations that they produce, we must investigate the ways in which different people in society relate to these. Fairclough (1989: 28) himself notes that power relations in a society are always part of a 'struggle'. But it could be argued that CDA tends to 
tell us little about this struggle, given its focus on elite texts. And it has been argued therefore that complexities in discourses have tended to be overlooked (Philo, 2007).

Media and communications scholars have long argued that how we engage with things like news is complex, may be fragmented and fleeting, and has always been difficult to research (Silverstone, 1994). Audience studies involving questionnaires or focus groups tend to produce artificial data where people respond in ways oriented to that research context. This does not resemble how media is taken up in their everyday lives. For CDA, which tends to study more sensitive topics such as racism, immigration or nationalism, it would be especially hard to carry out such decontextualized audience research. Here online ethnographies have been shown to be one way to access this kind of complexity (Pink, 2015). Such unobtrusive methods, it is argued, offer a way to find out what people say about the media when they are not consciously 'talking about the media' in a performative way, as they are when a media studies researcher interviews them (boyd, 2008).

In media studies, it has, for example, become commonplace to study television audiences through online discussion forums to research how people evaluate characters and stories (Bury, 2008). Hine (2008) looked at how audiences discussed television programs online, which has received harsh criticism by academics. Audiences expressed appreciation of the program but were also critical, and appeared highly aware of television conventions and how certain issues may be glossed over or shaped for the purposes of entertainment.

Taking on this kind of reception research in CDA, it could be argued, could be one way to address the problem of the critical analyst providing the single and authoritative reading. In the broader field of Critical Discourse Studies there has also been work, for example, on the way in which social media provides sites of alternative political views on things like racism, where mainstream new media tend to remain highly focused only on elite persons and officials (Van Zoonen, 2007). In CDA, some scholars have begun to explore the way that social media can be researched for the kinds of 
competing discourses that can be found around mainstream news media (Way, 2015). But as regards news, and specifically in CDA itself, this is an area that still remains to be explored.

Media scholars also indicate that even if our research interest is in the former top-down forms of media, such as broadcast news or television, it now also is a requirement to study this as part of the way it is integrated with other media platforms. This is in regard to the manner in which content is produced, how it is delivered and how it is consumed (Livingstone, 2004). Even formerly 'traditional' forms of media are now produced as part of multimedia, multiplatform content. For example, reality television shows are now created as a form of 'social television' (Selva, 2016: 161). These are built in a way to link with and foster social media activity. Reality television participants may themselves produce further self-promotional content through Twitter feeds designed to be picked up as news, which is then fed out to users and appears in the news section of their social media platform.

It has been argued that it is these patterns of content production, of news and other programming, and social media trending, which have reshaped public and civic debate (Van Dijck \& Poell, 2015: 1). Simply, if we want to understand the nature, not only of audience responses, but of news texts themselves, they must be seen as part of these cycles of interconnected media.

This new media landscape has been referred to as a kind of 'event society' (Murthy, 2012) where 'events' is a term used to capture the way that social media tends to contain a constant stream of passing, trivial events. These could be what Katz and Dayan (1985) would have called 'pseudo events'. Such events are the comments of a reality show participant, generic news stories with click bait captions such as 'do we really need to sleep', comments on your evening meal, a picture of your dog, the consumption of goods. The 'scan and go' clicktivism culture of social media described by Dean (2010) accounts then for the way that users engage with this stream of events and that they too 'interact' using the affordances of social media platforms to express 'like' or to tweet 'love heart' icons as a signal of political support. 
The nature of this landscape challenges CDA to consider which texts provide the most suitable kinds of data. In a top-down media environment, the study of elite texts would appear logical in looking for the ideology of the powerful. But in the social media landscape, we might argue, one important site of study is the configurations formed by these apparently trivial texts.

\section{Multimodal communication}

The kinds of shifts in communication we have looked at so far, the increased need to engage readers, the need to carry out research across interlocking platforms, provides another important challenge for CDA: discourses must be studied at a multimodal level. Van Leeuwen (2015) argues that there has been an 'aestheticization' of communication. This has its origins in advertising, where product marketing involves using attractive people, setting, and overall appealing designs. But this is now found across documents, texts, objects and media that were formerly highly functional (Machin \& Van Leeuwen, 2016). So too, media such as news outlets present content in newly aestheticized ways. And these aestheticized forms deploy design features as part of the ways in which they communicate discourses to audiences, as part of how they engage with them. Much time and resources go into the presentation of news in ways that integrates it with other kinds of content (Machin \& Polzer, 2015). And as these authors argue, such multimodal communication should not be viewed simply as dressing or style, but as part of the meanings communicated by content. And if we want to understand these multimodal discourses and the ideologies they carry, CDA will have to engage with these.

A multimodal level of analysis is also required at a different level. News found on web pages and social media may carry less running text and more chunks of texts connected to images, bulleted lists, graphics used to represent data in an accessible and fun way. In early 2017 Donald Trump communicated about levels of crime amongst black people via Twitter through a kind of data table, which also carried a cut-out of a black youth. This tweet generated responses in new outlets around the world and across social media, which also took the form of data tables, each aestheticized in its 
own way. CDA has always been interested in things like the representation of agency and causality. But in these graphics, these things are communicated symbolically by graphic elements and by the affordances of tables. CDA has begun to become more aware of the need to include multimodal data as part of its analysis. But the social media landscape calls for this to be the basic point of departure.

Multimodal analysis is also required if we accept that one challenge is to shift away from analysis based on single static texts, to those texts that form part of interlocking media, and platforms that will contain different kinds of content. So, what tools of analysis are required to analyze the discourses found across cycles of connected media, which include high levels of aestheticization, embedded film clips, and various kinds of data? Such studies have appeared, for example, Zhang et al (2015) looked at the way that a science news website presented science through discourses of entertainment and curiosity, and addressed a particular kind of community. Here 'knowledge' itself clearly becomes more about the kinds of processes of engagement and opinion we have discussed in earlier sections of this paper. Such meanings were never clearly explained in language, but were carried multimodally. Here language in texts could not be understood without the additional level of attention to multimodal discourse.

\section{Conclusion: the specific challenges for CDA}

CDA, we believe, offers an excellent way to identify what Van Dijk (1993) called the manipulation going on in texts. But it is clear that lack of academic engagement with context, i.e. how texts get produced and read, can lead to a rather simplistic level of analysis. This in itself can serve to weaken any project that seeks to identify and challenge dominant ideology in society, and the inequalities that it sustains in its own interest. In this sense, engaging with texts as they are part of the social media landscape we have described in this paper, is a clear part of the requirement for CDA.

This engagement with texts as a part of social media means seeing them as part of a transformation, not only of the media landscape but of our socio-political formation. Such texts represent communication where there has been a massive decline of former powerful state institutions and 
ratified knowledge, often established and naturalised over many centuries. Former centralized, topdown media have been replaced by interlocking platforms that carry many genres of content, using different media. And these will tend to be highly multimodal, using chunks of text, bullets, and lists combined with images and data graphics. Discourse will be increasingly multimodal as communication becomes more aestheticized, but sites of the dissemination of discourse can no longer best be accounted for by analysis of language alone.

While CDA scholars knew that traditional news texts or broadcasts operated in a one way, top-down fashion as regards how they disseminated discourses, we must now ask what kinds of flows are fostered and prevented in the configurations that are now emerging? What kinds of acceptance and resistance to these discourses are emerging? And clearly in this context, we may have opportunities to look at competing discourses on interlocking social media platforms that often, of course, feed into traditional media.

Finally, what kinds of elite interests are being served in this new socio-political formation? It has been argued that the very nature of neoliberal society is that all things are ruled by market logic (Jessop, 2007). Everything you know and do will be incorporated into this project. Of course, therefore, the elite remains the same. They are those whose interests are served by capitalist accumulation. But it has been argued that this market ideology now permeates all things. It becomes the discourses by which we manage our work, education, leisure time, education and domestic life. And social media appears to be playing a key role in this process.

Cauldry (2012) offered the term 'media practices' to think about the way that media become incorporated in our lives in mundane ways. For example, how 'searching online', 'latest update', 'sharing', 'community', 'liking', 'friending', 'most popular' may come to shape how we do, and think about, routine things, such as our relationships with other people and wider social relations. For Hjelmslev (1963), both discourses and the substances and forms used to communicate them, in other 
words the materials and technologies of communication, are one and the same as our consciousness.

As these change, so must the focus, tools and basic assumptions of CDA.

References

Anden-Papadopoulos, K. and Pantti, M (eds.) (2011) Amateur Images and Global News, Chicago, IL: University of Chicago Press.

Allen, S. (2006) Online News: Journalism and the Internet, New York, NY: McGraw-Hill.

Allan, S. (2013) Citizen Witnessing: Revisioning Journalism in Times of Crisis, Cambridge: Polity.

Beck, U. (1996) The Reinvention of Politics: Rethinking Modernity in the Global Social Order. Cambridge, MA: Polity Press.

Bouvier, G. (2015) What is a discourse approach to Twitter, Facebook, YouTube and other social media: connecting with other academic fields, Journal of Multicultural Discourses 10 (2), 149-162

boyd, d. (2008). Why youth (heart) social network sites: The role of networked publics in teenage social life. In D. Buckingham (Ed.), Youth, Identity, and Digital Media (pp. 119-142). Cambridge, MA: MIT Press.

Bruno, N. (2011) 'Tweet First, Verify Later: How Real-Time Information is Changing the Coverage of Worldwide Crisis Events', Reuters Institute for the Study of Journalism, Oxford: University of Oxford. http://reutersinstitute.politics.ox.ac.uk/publication/tweet-first-verify-later

Bury, R. (2008) 'Praise you like I should: Cyberfans and Six Feet Under'. In: Leverette, M. and Buckley, C. L. (eds) It's Not TV: Watching HBO in the Post-television Era, 190-208. New York, NY: Routledge.

Caldas-Coulthard, C. R. (1994) 'On reporting: the representation of speech in factual and factional narratives', In: Coulthard, R. M. (ed), Advances in Written Text Analysis, 295-308. London: Routledge.

Carlson, M. and Lewis, S. (2015) Boundaries of journalism: Professionalism, Practices and Participation. London: Routledge.

Cauldry, N. (2012) Media, Society, World: Social Theory and Digital Media Practice. London: Polity.

Curran, J. and Seaton, J. (2010) Power without Responsibility. London: Routledge.

Dean, J. (2010) Blog Theory. London: Polity.

Diamond, L. (2010) 'Liberation technology', Journal of Democracy, 21(3): 69-83.

Doctor, K. (2010) Newsonomics: Twelve New Trends That Will Shape the News You Get. New York, NY: Martin's Press.

Fairclough, N. (1989) Language and Power. London: Longman.

Fairclough, N. (1992) Discourse and Social Change. Oxford: Polity Press. 
Fairclough, N. (1995) Critical Discourse Analysis. London: Longman

Fairclough, N. (2000) 'Discourse, Social Theory, and Social Research: The Discourse of Welfare Reform', Journal of Sociolinguistics, 4(2): 163-195.

Fairclough, N. (2001) Language and Power. London: Longman.

Fishman, M. (1980) Manufacturing the News. Austin, TX: University of Texas Press.

Foucault, M. (1972) Archeology of Knowledge. London: Routledge.

Freidson, E. (2001) Professionalism, The Third Logic. Chicago, IL: University of Chicago Press.

Gillmor, D. (2006) How to use Flickr: The digital photography revolution. Boston, MA: Thomson Course Technology.

Hall, S. (1986) 'The Problem of Ideology - Marxism without Guarantees', Journal of Communication Inquiry, 10(2): 28-44.

Harcup, T. (2015) Journalism: Principles and Practice. London: Sage.

Harcup, T. and O'Neill, D. (2010) 'What Is News? Galtung and Ruge revisited', Journalism Studies, 2(2): 261-280.

Hermida, A. (2012) 'Tweets and Truth: Journalism as a Discipline of Collaborative Verification', Journalism Practice, 6(5-6): 659-668.

Hine, C. (2008) Systematics as Cyberscience: Computers, Change, and Continuity in Science. Cambridge, MA: MIT Press.

Hintz, A. (2016) 'Restricting Digital Sites of Dissent: Commercial Social Media and Free Expression', Critical Discourse Studies, 13(3): 325-340.

Hjelmslev, L. (1963) Prolegomena to a Theory of Language. Madison, WI: University of Wisconsin Press.

Jessop, B. (2007) State Power, London, Wiley.

Katz, E. and Dayan, D. (1985) 'Media Events: On the Experience of Not Being There', Religion, 15: 305-314.

Keller, J. (2011) 'Photojournalism in the New Media Economy', The Atlantic, 4 April, https://www.theatlantic.com/technology/archive/2011/04/photojournalism-in-the-age-of-new$\underline{\text { media/73083/ }}$

KhosraviNik, M. and Unger, J. W. (2015) 'Critical Discourse Studies and Social Media: Power, Resistance and Critique in Changing Media Ecologies'. In: Wodak, R. and Meyer, M. (eds), Methods of critical discourse studies, 205-233. Sage: London.

Kress, G. (2005) 'Gains and Losses: New Forms of Texts, Knowledge, and Learning', Computers and Composition, 22: 5-22. 
Lewis, J. M. W., Williams, A. and Franklin, R. A. (2008) 'A Compromised Fourth Estate? UK News Journalism, Public Relations and News Sources', Journalism Studies, 9(1): 1-20.

Linford, P. (2015) 'Trinity Mirror launches next phase of 'digital first' strategy', Hold the front page, 8 September, http://www.holdthefrontpage.co.uk/2015/news/trinity-mirror-launches-next-phase-ofdigital-first-strategy/

Livingstone, S. (2004) 'The Challenge of Changing Audiences: Or, What is the Audience Researcher to do in the Age of the Internet?', European Journal of Communication, 19(1): 75-86.

Loomis, C. J. (2007) 'Bloomberg's Money Machine', Fortune, 5 April, http://money.cnn.com/magazines/fortune/fortune archive/2007/04/16/8404302/index2.htm

Mautner, G. (2005) 'Time to Get Wired: Using Web-Based Corpora in Critical Discourse Analysis', Discourse \& Society, 16(6): 809-828.

Machin, D. and Niblock, S. (2006) News Production. London: Routledge.

Machin, D. and Polzer, L. (2015) Visual Journalism. London: Palgrave.

Machin, D. and Van Leeuwen, T. (2016) 'Multimodality, politics and ideology', Journal of Language and Politics, 15: 243-58.

Mayr, A. and Machin, D. (2012) The Language of Crime and Deviance: An Introduction to Critical Linguistic Analysis in Media and Popular Culture. London: Continuum.

McChesney, R. (2004) The Problem of the Media: U.S. Communication Politics in the 21st Century. New York, NY: Monthly Review Press.

Mortimer, N. (2014) 'Trinity Mirror makes "major investment" in online video as it admits current offering is a "poor example"', The Drum, 4 March, http://www.thedrum.com/news/2014/03/04/trinity-mirror-makes-major-investment-online-videoit-admits-current-offering-poor

Murthy, D. (2012) 'Towards a sociological understanding of social media: Theorizing Twitter', Sociology, 46(6): 1059-1073.

Newman, N. (2009) 'The Rise of Social Media and its Impact on Mainstream Journalism', Reuters Institute for the Study of Journalism, Oxford: University of Oxford. http://reutersinstitute.politics.ox.ac.uk/publication/rise-social-media-and-its-impact-mainstreamjournalism

Parry, K. (2012) 'The First 'Clean' War? Visually Framing Civilian Casualties in the British Press during the 2003 Iraq Invasion', Journal of War \& Culture Studies, 5(2): 173-187.

Paulussen, S. and Harder, R. A. (2014) 'Social Media References in Newspapers', Journalism Practice, 8(5): 542-551.

Philo, G. (2007) 'Can Discourse Analysis Successfully Explain the Content of Media and Journalistic Practice?', Journalism Studies, 8(2): 175-196. 
Picard, R. G. (2014) 'Twilight or New Dawn of Journalism: Evidence from the Changing News Ecosystem', Digital Journalism, 2(3): 273-283.

Pink, S. (2015) Doing Digital Ethnography. London: Sage.

Poell, T. (2015) 'Conceptualizing Forums and Blogs as Public Sphere', In: Lehmann, A-S., Raessens, J. Schafer, M. T., Van den Boomen, M.V.T. and Lammes, S., Digital Material, 239-251. Amsterdam: Amsterdam University Press.

Selva, D. (2016) 'Audience and Political Engement: An Analysis of Twitter Use during Italian Talk Shows', Television and New Media, 17(2): 159-173.

Silverstone, R. (1994) Television in Everyday Life. London, Routledge.

Simpson, P. and Mayr, A. (2010) Language and Power. London: Routledge.

Thurlow, C. (2011) 'Speaking of Difference: Language, Inequality and Interculturality', In: Halualani, R. and Nakayama, T. (eds), Handbook of Critical Intercultural Communication, 227-247. Oxford:

Blackwell.

Van Dijk, T. A. (1993) 'Principles of Critical Discourse Analysis', Discourse \& Society, 4(2): 249-283.

Van Dijk, T. A. (1995) 'The Aims of Critical Discourse Analysis', Japanese Discourse, 1: 17-27.

Van Dijk, T. A. (1998) Ideology: A Multidisciplinary Approach. London: Sage.

Van Dijk, T. A. (2005) Contextual Management in Discourse Production, In: Wodak, R. and Chilton, P. (eds), A New Agenda in (critical) Discourse Analysis, 71-100. Amsterdam: John Benjamins.

Van Dijck, J. (2013) The Culture of Connectivity: A Critical History of Social Media. Oxford: OUP.

Van Dijck, J. and Poell, T. (2015) 'Social Media and the Transformation of Public Space', Social Media + Society, 1(2): 1-5. http://journals.sagepub.com/doi/abs/10.1177/2056305115622482

Van Leeuwen, T. (2015) 'Multimodality'. In: Tannen, D., Hamilton, H. E. and Schiffrin, D. (eds), The Handbook of Discourse Analysis, 447-465. Hoboken, NJ: John Wiley \& Sons.

Van Zoonen, L. (2007) 'Audience reactions to Hollywood Politics', Media, Culture \& Society, 29(4): 531-547.

Way, L. C. S. (2015) 'YouTube as a Site of Debate through Populist Politics: The Case of a Turkish Protest Pop Video', Journal of Multicultural Discourses, 10(2): 180-196.

Widdowson, H. (1995) 'Review of Fairclough's Discourse and Social Change', Applied Linguistics. 16(4): 510-516.

Wodak, R. and Meyer, M. (eds) (2001) Methods in Critical Discourse Analysis. London: Sage.

Zhang, Y., Machin, D. and Song, T. (2015) 'Visual Firms of Address in Social Media Discourse: The Case of a Science Communication Website', Journal of Multicultural Discourses, 10(2): 236-252.

Žižek, S. (1997) The Plague of Fantasies. London, Verso. 